\title{
Evaluation of Efficacy of Rapid Antigen Test against RT-PCR and its Correlation with Cycle Threshold (CT) values: an Institutional Experience
}

\author{
Uma Shankar Saha*, Minakshi Gupta ${ }^{1}$, Minakshi Mishra ${ }^{2}$, \\ Rajan Chaudhry ${ }^{3}$, Sudhir Rai ${ }^{3}$, \\ ${ }^{1 *}$ Microbiologist, Department of Microbiology, TATA Main Hospital, Jamshedpur. \\ ${ }^{2}$ HOD and Pathologist, Department of Microbiology, TATA Main Hospital, Jamshedpur. \\ ${ }^{3}$ Medical Services, TATA main Hospital, Jamshedpur, India
}

\begin{abstract}
Rapidly increasing COVID-19 or SARS-CoV-2 in whole world caused a tremendous pressure on existing diagnostic setup to give accurate diagnosis on time by gold standard RT-PCR technique forcing scientist to think beyond RT-PCR which ultimately ended with invent of Rapid antigen test which can give about $100 \%$ specific and rapid result but may miss many case due to low sensitivity.

So we wanted to evaluate the Rapid antigen test against RT-PCR for its diagnostic accuracy. We followed standard procedure for sample collection, Rapid antigen test and RT-PCR test.

In about one and half month span we collected 554 antigen negative samples in our hospital. About 13\% sample (74/554) turned out as positive by RT-PCR test. About $40 \%$ (30/74) positive samples had low $\mathrm{Ct}$ value $(<25)$ indicating higher viral load present in those patients.

Above findings indicate that only antigen test will miss a significant portion of positive cases with higher viral load which may complicate the pandemic by unknowingly spreading the virus within the society. So we should try to improve our infrastructure to carry out more RTPCR test so we can detect more cases to identify and isolate them from others to prevent or slowdown the transmission chain.
\end{abstract}

Keywords: Rapid antigen test, RT-PCR, SARS-CoV-2, CT values, COVID-19.

*Author for Correspondence. E-mail: uma.saha@tatasteel.com

This work is licensed under a Creative Commons Attribution-Noncommercial-Share Alike 4.0 International License. 


\section{Introduction:}

After first case of severe unexplained pneumonia was reported in December 2019, the rapidly emerging disease was spreading day by day and caused tremendous public health challenges worldwide. On January 82020 , the pathogen was identified by sequencing and named as the novel (new) coronavirus 2019 (2019-nCoV). On February 12, 2020, International Committee on Taxonomy of Viruses officially named this novel (new) corona virus as SARS-CoV-2 (Severe Acute Respiratory Syndrome Corona virus 2), and World Health Organization also declared the disease as coronavirus disease 2019 (COVID-19). [1] Till now, millions of cases have been confirmed worldwide including severe and death cases. It is a rapidly spreading disease and mainly spread through droplets and contact. Timely detection and isolation of cases and their contacts are considered crucial to control this unprecedented pandemic. Currently the gold standard for the detection of SARS-CoV-2 is viral RNA amplification by real-time RT-PCR (RT-PCR) and requires few hours before releasing results [2]. With increasing number of cases, the existing infrastructure to do RT-PCR failed to handle the test load, resulting in long waiting for reports and ultimately affecting the preventive measures for containment.

There was search for a rapid, and easy-to-perform diagnostic tools that can be used to test large numbers of samples in a short period of time. Antigen test came out as an alternative test. With time, many kits have been developed with varying sensitivity and specificity and are being used for screening. From different studies, it has been seen that most kits in use are highly specific (near 100\%) but has low sensitivity (ranging from $35-80 \%$ ), causing false negative result. As per ICMR guidelines also, positive antigen test should be considered as true positive but negative cases need to be evaluated and confirmed by RT-PCR.

So, in this study, all antigen positive cases were taken as true positive and RT-PCR was not conducted. For all antigen negative suspected cases, an additional sample was collected for RTPCR.

Our aim was to detect diagnostic accuracy of a rapid antigen test for SARS-CoV-2, keeping RT-PCR as gold standard and to see, if there was any correlation with cycle threshold values of RT-PCR positive samples.

\section{Material and Methods:}

\section{Inclusion criteria:-}

1. COVID samples taken between mid- September till end October 2020, were included in the study.

2. All patients who presented with respiratory symptoms or other symptom suggestive of COVID-19 infection were considered for this study irrespective of age or sex. 


\section{Exclusion criteria:-}

1. Only single sample for Rapid antigen or RT-PCR was taken.

2. Patient who came with COVID-19 antigen or RT-PCR report done in outside laboratory.

\section{Kits and materials used:}

Antigen kit:- STANDARD Q COVID-19 antigen kit from SD Biosensor healthcare Pvt. Ltd, Republic of Korea was used. Kit contains immunochromatography card, swabs, buffer tube with dropper.

VTM:- Viral transport medium for RTPCR sample collection were from BiO-MED PRIVATE LIMITED, INDIA.

RNA extraction kit: Geno Sens ${ }^{\circledR}$ Viral RNA Extraction Mini Kit from Genome Diagnostic Private Limited, INDIA.

COVID-19 RT-PCR kit: "STANDARD M nCoV Real-Time Detection kit, for laboratory testing for 2019 novel coronavirus (2019-nCoV) in humans" contain all reagents for PCR including nCoV primers/probes ORF1ab (RdRp) gene, E gene and Internal controls.

\section{Sample collection and testing protocol:-}

All patients after being evaluated by on duty physician for presence of any respiratory symptoms and/or fever and any risk factor for SARS-CoV-2 infection, was advised for COVID-19 screening as per hospital COVID protocol at our TATA main hospital, Jamshedpur following ICMR guidelines [3].Samples were collected by our trained technician following standard method of sample collection as laid by ICMR.

Nasopharyngeal and oral swabs were taken for RAT and RT-PCR from patients in COVID screening area. Rapid antigen test was conducted for every sample taken there in in-situ laboratory at emergency. Results were evaluated and reported as POSITIVE or NEGATIVE.

All antigen POSITIVE cases were considered as true positive as claimed by maker as well as validated by ICMR, so no RT-PCR test was conducted for positive samples. For all antigen NEGATIVE suspected cases, RT-PCR was conducted from $2^{\text {nd }}$ sample collected in viral transport medium (VTM). Samples were subjected to RT-PCR and patients were shifted to special suspect ward until RT-PCR result was available.

\section{Results:}

Total 554 samples tested negative with Rapid card. Out of 554 antigen negative, 74 (13.35\%) samples turned out to be positive in RT-PCR, remaining 480were negative (Figure 1). Among 74 RTPCR positive but antigen negative cases when we did evaluation of CT value for RdRP and E gene and studied their pattern, we found 30 samples had CT value $\leq 25(40.54 \%)$ as low as 21 and 41 samples $(55.40 \%)$ had $>25$ to $\leq 30$, and 3 sample $(4.04 \%)$ had $>30$. (Figure 2 ) 
Total samples 554

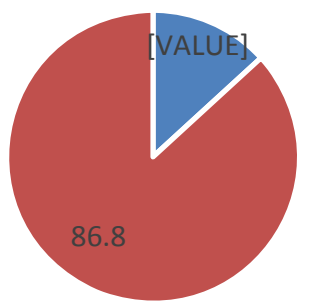

- RT-PCR POSITIVE (Total 74)

- RTPCR NEGATIVE (Total 480)

Figure 1: Percentage of RT-PCR negative and positive samples.

\section{Total positive samples 74}

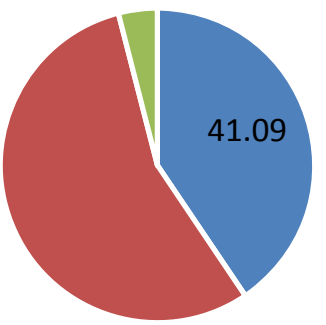

- CT values $\leq 25$ (Total 30)

- $C T$ values $>25$ to $\leq 30$ (total 41 )

CT values >30 (Total 03)

Figure 2: Sub classification of Positive samples according to CT values in RT-PCR.

Age and sex distribution among 74 positive cases are as follows (Table 1).

Line Age group $>60$ years was most prevalent followed by age group 41-60 years among "RT-PCT positive \&antigen negative" cases. Male $(\mathrm{n}=54)$ was about 2.5 times more than female $(n=20)$.

Table 1: Age and sex distribution among positive samples.

\begin{tabular}{|c|c|c|c|c|c|c|}
\hline Age group & Number & Male $(\mathrm{M})$ & Female (F) & CT $<=25$ & CT $>25-30$ & CT $>30$ \\
\hline$<10$ & 2 & 2 & 0 & 1 & 1 & 0 \\
\hline $11-20$ & 1 & 1 & 0 & 0 & 1 & 0 \\
\hline $21-40$ & 9 & 7 & 2 & 3 & 6 & 0 \\
\hline $41-60$ & 27 & 22 & 5 & 13 & 12 & 2 \\
\hline$>60$ & 35 & 22 & 13 & 13 & 21 & 1 \\
\hline
\end{tabular}

Though RT-PCR was not performed for positive antigen test, for a small number $(\mathrm{n}=5)$ we did RT-PCR test, which all gave positive result with $\mathrm{CT}$ value $<21$ in all cases. (Table 2 )

Table 2: CT value of Rapid Antigen positive samples.

\begin{tabular}{|l|c|c|}
\hline SAMPLES & CT value of RDRP gene & CT value of E gene \\
\hline SAMPLE 1 & 15 & 15 \\
\hline SAMPLE 2 & 15 & 16 \\
\hline SAMPLE 3 & 16 & 16 \\
\hline SAMPLE 4 & 19 & 19 \\
\hline SAMPLE 5 & 11 & 12 \\
\hline
\end{tabular}




\section{Discussion:}

To control COVID-19 pandemic, easy, rapid and cost-effective diagnostic approaches are very much needed. POCT test like antigen detection of SARS-CoV-2 are quite promising; however, main concern is the false-negative result due to low viral loads [4-8]. Francesco Cerutti et al, observed in their study that CT values for discordant RT-PCR-positive/R-Ag-negative samples was high (32.1, IC95 \% 32.05-32.15; range 23.7-38.1)[9]. In few studies, it has been seen that low viral load is consistent with low viable virus and low infectiousness [10,11].Jared Bullard et al, showed that There was no growth of virus in vero cell line in samples with a $\mathrm{Ct}>24$. [10]. But in our study we observed that antigen test can give false negative report even for a significant portion $(40 \%)$ of patient with low CT values $(<25)$ /moderate viral load also. We excluded preanalytical error by collecting samples in same time by same trained technician. As per our observation, antigen kit was not able to detect RT-PCR positive samples with CT value $>21$ as positive. This would have resulted in missing about $13 \%$ positive case (with CT value $>21$ ) if all cases were tested only by antigen method. These patients with moderate viral load may carry viable virus with them and may spread the virus in society. So antigen negative but RT-PCR positive does not always indicate low viral load or low infectiousness. They may have moderate to high viral load even if they show antigen negative as seen in our study. Higher age group and Male sex was mostly affected but it may not have any correlation with false negative result, they are usual susceptible group in population.

\section{Conclusion:}

From this observation we can conclude that mild symptomatic patients or asymptomatic high risk contact patient should go for RT-PCR test if antigen negative. Otherwise they may go on spreading the virus with false sense of being negative endangering others in society. So we need more sensitive rapid point of care test (POCT) to detect covid-19 or we should try to enhance the RT-PCR facility so we can do more test in RT-PCR and can give early report.

Limitation: Viral viability test or cell culture was not conducted due to infrastructure limitation to determine if the low CT value samples really had viable virus.

\section{Conflict of interest- No}

Financial support- No extra financial support taken.

Acknowledgement: We would first like to acknowledge ICMR for giving us permission to conduct antigen and RT-PCR test for COVID-19. Next we would like to acknowledge the support given to us by our administration to develop the infrastructure in short time. We would like to thank VRDL laboratory in MGM medical college, Jamshedpur for supporting us during initial phase to train our few technician to do RT-PCR test. And most importantly our technical staff who worked hard day and night from sample collection to testing to make this successful. 


\section{References:}

1. Naming the coronavirus disease (COVID-19) and the virus that causes it: WHO. https://www.who.int/emergencies/diseases/novel-coronavirus-2019/technical- guidance/naming-thecoronavirus-disease-(covid-2019)-and-the-virus-that-causes-it

2. Corman, V. M., Landt, O., Kaiser, M., Molenkamp, R., Meijer, A., Chu, D. K., Bleicker, T., Brünink, S., Schneider, J., Schmidt, M. L., Mulders, D. G., Haagmans, B. L., van der Veer, B., van den Brink, S., Wijsman, L., Goderski, G., Romette, J. L., Ellis, J., Zambon, M., Peiris, M., ... Drosten, C. 2020, "Detection of 2019 novel coronavirus (2019-nCoV) by real-time RT-PCR." Euro surveillance: Bulletin Europeen sur les maladies transmissibles = European communicable disease bulletin, 25(3), 2000045. https://doi.org/10.2807/1560-7917.ES.2020.25.3.2000045

3. COVID-19 - Sample collection guidelines- Indian Council of Medical Research, April 1, 2020. http://www.nie.gov.in/images/leftcontent_attach/COVID-SARI_Sample_collection_SOP_255.pdf

4. Scohy, A., Anantharajah, A., Bodéus, M., Kabamba-Mukadi, B., Verroken, A., \& Rodriguez-Villalobos, H. 2020,"Low performance of rapid antigen detection test as frontline testing for COVID-19 diagnosis." Journal of clinical virology: the official publication of the Pan American Society for Clinical Virology, 129, 104455. https://doi.org/10.1016/j.jcv.2020.104455

5. Lambert-Niclot, S., Cuffel, A., Le Pape, S., Vauloup-Fellous, C., Morand-Joubert, L., Roque-Afonso, A. M., Le Goff, J., \& Delaugerre, C. 2020,"Evaluation of a Rapid Diagnostic Assay for Detection of SARS-CoV-2 Antigen in Nasopharyngeal Swabs." Journal of clinical microbiology, 58(8), e00977-20. https://doi.org/10.1128/JCM.00977-20

6. Harcourt, J., Tamin, A., Lu, X., Kamili, S., Sakthivel, S. K., Murray, J., Queen, K., Tao, Y., Paden, C. R., Zhang, J., Li, Y., Uehara, A., Wang, H., Goldsmith, C., Bullock, H. A., Wang, L., Whitaker, B., Lynch, B., Gautam, R., Schindewolf, C., ... Thornburg, N. J. 2020, "Severe Acute Respiratory Syndrome Coronavirus 2 from Patient with Coronavirus Disease, United States.” Emerging infectious diseases, 26(6), 1266-1273. https://doi.org/10.3201/eid2606.200516

7. Mavrikou, S., Moschopoulou, G.,Tsekouras, V., \&Kintzios, S. 2020,"Development of a Portable, UltraRapid and Ultra-Sensitive Cell-Based Biosensor for the Direct Detection of the SARS-CoV-2 S1 Spike Protein Antigen.” Sensors (Basel, Switzerland), 20(11), 3121. https://doi.org/10.3390/s20113121.

8. Mertens, P., De Vos, N., Martiny, D., Jassoy, C., Mirazimi, A., Cuypers, L., Van den Wijngaert, S., Monteil, V., Melin, P., Stoffels, K., Yin, N., Mileto, D., Delaunoy, S., Magein, H., Lagrou, K., Bouzet, J., Serrano, G., Wautier, M., Leclipteux, T., Van Ranst, M., ... LHUB-ULB SARS-CoV-2 Working Diagnostic Group. 2020,"Development and Potential Usefulness of the COVID-19 Ag Respi-Strip Diagnostic Assay in a Pandemic Context." Frontiers in medicine, 7, 225. https://doi.org/10.3389/fmed.2020.00225

9. Cerutti, F., Burdino, E., Milia, M. G., Allice, T., Gregori, G., Bruzzone, B., \&Ghisetti, V. 2020,“Urgent need of rapid tests for SARS CoV-2 antigen detection: Evaluation of the SD-Biosensor antigen test for SARS-CoV-2. ," Journal of clinical virology : the official publication of the Pan American Society for Clinical Virology, 132, 104654. https://doi.org/10.1016/j.jcv.2020.104654

10. La Scola, B., Le Bideau, M., Andreani, J., Hoang, V. T., Grimaldier, C., Colson, P., Gautret, P., \&Raoult, D. 2020,"Viral RNA load as determined by cell culture as a management tool for discharge of SARS- 
CoV-2 patients from infectious disease wards." European journal of clinical microbiology \& infectious diseases : official publication of the European Society of Clinical Microbiology, 39(6), 1059-1061. https://doi.org/10.1007/s10096-020-03913-9

11. Bullard, J., Dust, K., Funk, D., Strong, J. E., Alexander, D., Garnett, L., Boodman, C., Bello, A., Hedley, A., Schiffman, Z., Doan, K., Bastien, N., Li, Y., Van Caeseele, P. G., \&Poliquin, G. 2020,"Predicting Infectious Severe Acute Respiratory Syndrome Coronavirus 2 From Diagnostic Samples." Clinical infectious diseases: an official publication of the Infectious Diseases Society of America, 71(10), 2663-2666. https://doi.org/10.1093/cid/ciaa638 